\title{
Phenolic compounds isolated from fermented blueberry juice decrease hepatocellular glucose output and enhance muscle glucose uptake in cultured murine and human cells
}

\author{
Abir Nachar ${ }^{1,2}$, Hoda M. Eid ${ }^{1,2,3}$, Melinda Vinqvist-Tymchuk ${ }^{4}$, Tri Vuong ${ }^{5}$, Wilhelmina Kalt ${ }^{4}$, Chantal Matar ${ }^{5}$ \\ and Pierre S. Haddad ${ }^{1,2^{*}}$
}

\begin{abstract}
Background: We recently reported that blueberry juice fermented (FJ) with Serratia vaccinii bacterium has antidiabetic activities both in vivo and in vitro. The purpose of this project was to elucidate the effect of FJ on glucose homeostasis in liver and skeletal muscle cells and to identify active fractions/compounds responsible for this effect.

Methods: FJ was fractionated using standard chromatography procedures. Hepatic (H4IIE, HepG2) and skeletal muscle cells (C2 (12) were treated with maximum non-toxic concentrations of FJ, fractions and isolated compounds thereof. Glucose-6-phosphatase (G6Pase) activity was measured using glucose oxidase method. To measure glucose uptake and glycogen synthase (GS) activity, radioactive assays were used.

Results: Fractionation of FJ yielded seven fractions. FJ and its phenolic fractions F2, F3-1 and F3-2 respectively inhibited G-6Pase by 31, 45, 51 and 26\%; activated GS by 2.3-, 2.3-, 2.2- and 2-fold; and stimulated glucose uptake by $19,25,18$ and $15 \%$, as compared to DMSO vehicle control. Subfractionation of the active fractions yielded 4 compounds (catechol, chlorogenic, gallic and protocatechuic acid). Catechol, yielding the greatest bioactivity in G6Pase and glucose uptake assays, decreased G6Pase activity by $54 \%$, increased GS by 2-fold and stimulated glucose uptake by $44 \%$ at $45.5 \mu \mathrm{M}$.
\end{abstract}

Conclusions: This study identifies novel potential antidiabetic compounds that can help standardize FJ.

Keywords: Diabetes, Glucose homeostasis, Glucose-6-phosphatase, Glycogen Synthase, Glucose transport

\section{Background}

Type 2 diabetes (T2D) is a chronic metabolic disease that affects 382 million people worldwide and is associated with many complications, especially cardiovascular diseases [1]. Insulin resistance plays a major role in the physiopathology of type 2 diabetes. It is associated with

\footnotetext{
* Correspondence: pierre.haddad@umontreal.ca

${ }^{1}$ Natural Health Products and Metabolic Diseases Laboratory, Department of Pharmacology and Physiology, Université de Montréal, Station Centre-Ville, P.O. Box 6128, Montréal, Québec H3C 3J7, Canada

${ }^{2}$ Canadian Institutes of Health Research Team in Aboriginal Antidiabetic Medicines and Montreal Diabetes Research Center, Montreal, Canada Full list of author information is available at the end of the article
}

an impaired insulin stimulation of glucose transport in muscle and fat as well as an impaired suppression of hepatic glucose production [2]. Nowadays, several people are using natural health products alone or in combination with their hypoglycemic drugs to manage their T2D. Currently, more than one third of Canadian diabetic patients are using alternative medicine [3, 4].

Members of the Vaccinium genus (family Ericaceae), notably Vaccinium angustifolium Ait (Canadian lowbush blueberry), are well known for their antidiabetic activities and have been used in the traditional medicine of many populations to treat T2D [5-8]. Previous studies 
have shown that different parts of the $V$. angustifolium plant reduces insulin resistance in obese rats [9] and possess insulin-like, glitazone-like and cytoprotective effects [10]. Blueberry fruits are rich in phenolic compounds with antidiabetic properties $[8,11]$. Interestingly, the biotransformation of blueberry juice by a bacterium called Serratia vaccinii was found to greatly increase its content in phenolic compounds and its antioxidant activity [12].

This process also had an impact on the antidiabetic potential of blueberry juice. Indeed, fermented blueberry juice (FJ), in contrast to normal juice, stimulated glucose uptake in muscle cells and adipocytes using an insulinindependent pathway implicating the phosphorylation of AMP-activated protein kinase (AMPK) [13]. This antidiabetic effect was validated in an animal model using KKAy hyperphagic mice [14].

Glucose homeostasis results from equilibrium between the intestinal absorption of glucose, its production by the liver and its utilization by peripheral tissues such as muscle and fat [15]. Insulin regulates hepatic glucose production and storage. It inhibits some transcription factors like the forkhead family and the Peroxisome proliferator-activated receptor-gamma coactivator- $1 \alpha$ (PGC-1 $\alpha$ ) leading to a decrease in the activity of Glucose-6-phosphatase (G6Pase), a key enzyme implicated in hepatic glucose production $[16,17]$. On the other hand, insulin signaling phosphorylates glycogen synthase kinase-3 (GSK-3) leading to the activation of glycogen synthase (GS), a key enzyme implicated in glucose storage [18]. In addition, insulin regulates glucose uptake and utilization in muscle through the stimulation of glucose transporter 4 (GLUT4) translocation to the plasma membrane in order to mediate facilitative glucose diffusion [19].

In continuity with aforementioned studies on FJ in muscle cells and adipocytes, the aim of this project is to elucidate the antidiabetic action of FJ at the level of glucose homeostasis in cultured hepatocytes and muscle cells. Importantly, our purpose is to identify active fractions and compounds responsible of the antidiabetic activity of FJ.

\section{Methods}

\section{Cell culture}

All cell lines used - H4IIE (rat hepatoma), HepG2 (human hepatoma) and C2C12 (murine skeletal myoblasts) - were purchased from American Type Culture Collection (ATCC; Manassas, VA, USA). H4IIE cells were grown in a high glucose Dubelcco's Modified Eagle Medium (DMEM) containing 10\% Fetal Bovin Serum (FBS) and 0.5\% antibiotics (PS: Penicillin $100 \mathrm{U} / \mathrm{mL}$, Streptomycin $100 \mu \mathrm{g} / \mathrm{mL}$ ). HepG2 cells were grown in DMEM/F12 (50/50) medium, containing 10 FBS and $0.5 \%$ PS. On the other hand,
C2C12 myocytes were cultured in DMEM medium containing $10 \mathrm{FBS}, 10 \mathrm{HS}$ and $0.5 \%$ PS then switched to DMEM medium containing $2 \%$ HS to initiate differentiation. Glucose uptake assay was performed on differentiated myotubes at the $7^{\text {th }}$ day of differentiation. All cells were cultured and incubated at $37{ }^{\circ} \mathrm{C}$ with $5 \% \mathrm{CO}_{2}$ in 12 well plates for glucose uptake and G6Pase experiments and in 6-well plates for GS experiments. Overnight treatment (16-18 h) with the different samples was initiated prior to the determinations.

\section{Preparation of fermented blueberry juice}

Mature lowbush blueberry fruits were purchased from Cherryfield Foods Inc. (Cherryfield, Maine, USA). The species was identified by the plant taxonomist Dr. Alain Cuerrier (Montreal Botanical Garden). The frozen fruit preparation represents a homogeneous mixture of several genotypes provided by many wild blueberry producers from Canada and Northeastern United States. We selected this starting material because it appropriately represents what is regularly used in the industry to prepare commercial wild blueberry juice. For the purposes of this study, blueberry fruit mixture (hereafter called juice) was prepared by blending the fruits (100 g) with an equivalent quantity (100 g) of Minimal Broth Davis without dextrose (MM) (Difco Laboratories, Detroit, MI, USA). The fruit mixture was then centrifuged to remove insoluble particles. The resulting juice was sterilized using $0.22 \mu \mathrm{m}$ Express Millipore filters (Millipore, Etobicoke, ON, Canada).

Serratia vaccinii were cultured as previously described [12]. The juice was inoculated with a saturated culture of Serratia vaccinii at $(7.5 \pm 0.3) \log$ CFU ml - 1 corresponding to $2 \%$ of the total juice volume. A control flask was prepared under the same conditions but without inoculation. The blueberry preparations were incubated in a Lab-Line low-temperature benchtop incubated shaker (Lab-Line Instruments, Inc, Melrose Park, IL, USA) in 250-ml flasks at $22{ }^{\circ} \mathrm{C}, 120 \mathrm{rev}$ min -1, under aerobic conditions. After a 4 day fermentation period, the FJ was sterilized by $0.22 \mu \mathrm{m}$ filtration as detailed elsewhere [12].

In order to facilitate the handling and insure the stability of the blueberry preparations, they were freeze-dried to produce powdered material that was kept at $-20{ }^{\circ} \mathrm{C}$ until use.

\section{Fractionation of FJ and identification of active compounds}

Organic solvents were purchased from Fisher Scientific (Burlington, ON, Canada), unless otherwise mentioned. Normal blueberry juice has been partially characterized elsewhere $[12,13,20,21]$. In the present studies, we carried out further phytochemical analysis using HPLC as described below. Figure 1 shows the fractionation 


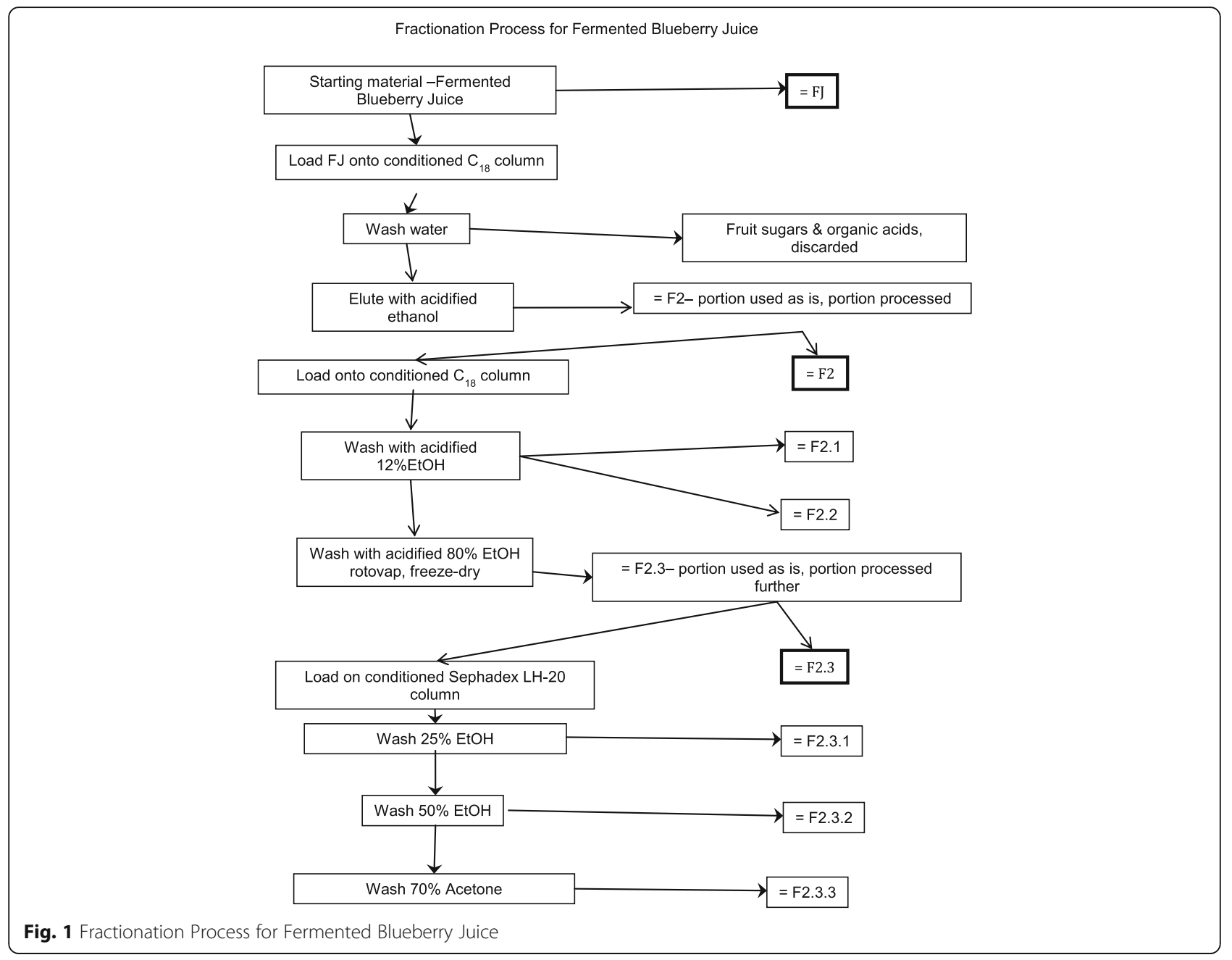

scheme that was carried out to identify active compounds present in fermented blueberry juice (FJ). The starting material for the fractionation process was either normal blueberry juice prepared from wild blueberries (the control Juice, CJ), or the FJ in batches of approximately $500 \mathrm{ml}$. These were placed onto $29.5 \mathrm{~cm} \times 5 \mathrm{~cm}$ chromatography columns (pre-conditioned with 1 column volume methanol then 2 column volumes water) containing Waters preparative $\mathrm{C} 18$ resin $(125 \AA$, 55 $105 \mu$ ) then washed with 2 column volumes of water, which was sufficient to remove sugars and organic acids (discarded). The phenolic compounds were eluted from the column using 1.2 column volumes of $13 \mathrm{mM}$ trifluoroacetic acid (Sigma Aldrich, Oakville, ON) in ethanol. The ethanol eluent was dried using rotary evaporation and lyophilized to give the Phenolic fraction (F2). The CJ underwent no further fractionation after this initial step. On the other hand, a portion of F2 was dissolved in water and further fractionated on $\mathrm{C} 18$ column as outlined above. The first subfraction (F2.1) was eluted using 4 column volumes of $0.16 \mathrm{M} \mathrm{HCl}$ (Ricca
Chemical Company, Texas, USA) and 2.06 $\mathrm{M}$ ethanol in water. This subfraction was composed mainly of gallic acid, protocatechuic acid, and catechol, as confirmed by HPLC (comparing retention times and UV-vis profiles of the peaks to standards). The next subfraction (F2.2) was eluted using an additional 2 column volumes of $0.16 \mathrm{M}$ $\mathrm{HCl}$ and $2.06 \mathrm{M}$ ethanol in water and was rich in chlorogenic acid (as confirmed by HPLC). The remaining bound materials, mainly flavonoids, were eluted using $0.16 \mathrm{M} \mathrm{HCl}$ and $13.7 \mathrm{M}$ ethanol in water and were called the flavonoid fraction (F2.3). The three fractions were dried using rotary evaporation and lyophilisation. Next, a portion of the F2.3 fraction was dissolved in $4.28 \mathrm{M}$ ethanol and applied to a $34.5 \mathrm{~cm} \times 5 \mathrm{~cm}$ lipophilic Sephadex column (LH-20, 25-100 $\mu$, Sigma Aldrich, Oakville, ON, Canada). $\mathrm{HCl}$ was neutralized and three fractions were collected. The first fraction enriched in anthocyanins (F2.3.1) was eluted using 7 column volumes of 4.28 M ethanol. The second fraction enriched in heteropolymers (F2.3.2) was then eluted using 3 column volumes of $8.56 \mathrm{M}$ ethanol. Finally, a third fraction 
enriched in proanthocyanidins (F2.3.3) was eluted using 3 column volumes of $9.53 \mathrm{M}$ acetone. All three fractions were dried using rotary evaporation and lyophilisation.

\section{HPLC analysis of normal and fermented blueberry juice}

The HPLC system used was an Agilent 1100 binary pump system (Agilent Technologies, Mississauga, ON, Canada) with thermostatted column chamber, refrigerated autosampler, degasser, and DAD detection. Samples were separated on an Agilent Zorbax SB-C18 $2.1 \times 50 \mathrm{~mm}$ $1.8 \mu$ column held at $26{ }^{\circ} \mathrm{C}$. Samples were held at $4{ }^{\circ} \mathrm{C}$ in the autosampler. Elution was done using a two solvent gradient (solvent A was $8 \mathrm{ml}$ trifluoroacetic acid (TFA) per litre water ( $\mathrm{pH} 1.35)$, solvent $B$ was $6.8 \mathrm{ml}$ TFA per liter acetonitrile) at a flow rate of $0.4 \mathrm{~mL} / \mathrm{min}$ as follows: 5-10\% B (0-12.5 min), 10-20\% B (12.5-43.75 min), 20100\% B (43.75-45 min), hold 100\% B 5 min, 100-5\% B (50-51 $\mathrm{min}$ ), re-equilibrating $9 \mathrm{~min}$ before the next injection. The following wavelengths were monitored: $280 \mathrm{~nm}$ (phenolics), $360 \mathrm{~nm}$ (flavonols), and $520 \mathrm{~nm}$ (anthocyanins), and as well full spectra were recorded from 190 to $600 \mathrm{~nm}$. Designated pure compounds were quantified using authentic standards (Sigma Aldrich, Oakville, ON, Canada).

\section{Cytotoxicity assay (LDH)}

The cytotoxicity assay was based on a lactate dehydrogenase (LDH) release kit (LDH Colorimetric Kit; Roche, Mannheim, Germany) and served to determine maximum non-toxic concentration of each sample in H4IIE, HepG2 and $\mathrm{C} 2 \mathrm{C} 12$ cells. As was described previously [22], the cells were treated overnight (16-18 h) with CJ, FJ, fractions thereof, or pure compounds at different concentrations. The culture media were collected separately for each condition and kept on ice (representing released LDH from cells).

Then the cells were lysed by adding culture medium with $1 \%$ Triton, for $10 \mathrm{~min}$ at $37{ }^{\circ} \mathrm{C}, 5 \% \mathrm{CO}_{2}$ (representing cellular $\mathrm{LDH})$. All the samples were centrifuged at $250 \times g, 4{ }^{\circ} \mathrm{C}$ for $10 \mathrm{~min}$ and kept on ice in Eppendorf tubes. The ratio of released $\mathrm{LDH}$ to total $\mathrm{LDH}$ (total $\mathrm{LDH}=$ released $\mathrm{LDH}+$ cellular $\mathrm{LDH}$ ) was calculated for each condition and results normalized to the values obtained from cells treated with the vehicle control (DMSO), always present at a final concentration of $0.1 \%$. Maximum non-toxic concentrations for each sample were the highest ones that yielded LDH release comparable to that of DMSO controls.

\section{Glusose-6-phosphatase (G6Pase) activity}

H4IIE cell line was used to measure the activity of G6Pase. Confluent cells were treated overnight (16$18 \mathrm{~h}$ ) with DMSO 0.1\% (vehicle control), insulin $100 \mathrm{nM}$ (positive control), CJ, FJ, each of the seven fractions (at
$5 \mu \mathrm{g} / \mathrm{mL}$ ) or each of the four pure compounds, all at their maximal non-toxic concentrations (Additional file 1: Table S1). After the treatment, cells were rinsed with PBS then lysed using a $15 \mathrm{mM}$ phosphate buffer containing $0.05 \%$ Triton and $1.3 \mathrm{mM}$ Phenol $(\mathrm{pH}=6.5)$. A glucose-6phosphate-containing buffer $(200 \mathrm{mM})$ was then added to the cell lysates for $40 \mathrm{~min}$ at $37^{\circ} \mathrm{C}$; G-6-P contained in this buffer served as a substrate for endogenous G6Pase to yield glucose. A Wako AutoKit Glucose colorimetric assay (Wako Chemicals, Richmond, VA, USA) was used to determine the quantity of glucose generated in this reaction according to manufacturers' recommendations. The BCA method was used to determine the protein content for each condition. Results were expressed relative to vehicle control (DMSO 0.1\%).

\section{Glycogen Synthase (GS) activity}

HepG2 cells were used to measure GS activity since this cell line exhibit a better expression of this enzyme compared to the H4IIE hepatocytes [23]. After achieving confluence in 6 well plates, the cells were treated overnight $(16-18 \mathrm{~h})$ with either vehicle control (DMSO 0.1\%), the maximal non-toxic concentrations of CJ, FJ, each of the seven fractions $(5 \mu \mathrm{g} / \mathrm{mL})$ or each of the four pure compounds (Additional file 1: Table S1). Treatment with insulin at $100 \mathrm{nM}$ for $15 \mathrm{~min}$ was used as a positive control. After treatment, cells were rinsed with PBS then lysed in a buffer solution containing $50 \mathrm{mM}$ glycylglycine, $100 \mathrm{mM}$ sodium fluoride, 20 mM EDTA, 0.5\% glycogen, pH 7.4 and a complete protease inhibitor cocktail added just before the assay. The lysates were centrifuged at $1000 \times g$ for $20 \mathrm{~min}$ at $4{ }^{\circ} \mathrm{C}$. After centrifugation, $30 \mu \mathrm{L}$ of supernatant from each condition were added to $100 \mu \mathrm{L}$ of a specific buffer solution to measure active GS (25 mM glycylglycine, $0.275 \mathrm{mM}$ UDP-glucose, $0.12 \mu \mathrm{Ci} / \mathrm{mL} \mathrm{U}-{ }^{14} \mathrm{C}$ UDP-glucose, $1 \%$ glycogen, $1 \mathrm{mM}$ EDTA, $10 \mathrm{mM}$ sodium sulfate, $\mathrm{pH}$ 7.5) and another $30 \mu \mathrm{L}$ of supernatant were added to $100 \mu \mathrm{L}$ of a specific buffer solution to measure total GS $(25 \mathrm{mM}$ Tris, $5 \mathrm{mM}$ UDP-glucose, $0.12 \mu \mathrm{Ci} / \mathrm{mL}$ U- ${ }^{14} \mathrm{C}$ UDPglucose, $1 \%$ glycogen, $3 \mathrm{mM}$ EDTA, $5 \mathrm{mM}$ glucose-6phosphate, $\mathrm{pH}$ 7.9). The tubes were incubated in a water bath at $30{ }^{\circ} \mathrm{C}$ for $120 \mathrm{~min}$. After incubation, $90 \mu \mathrm{L}$ of the mix for each condition was transferred on Whatman $31 \mathrm{ET}$ chr $2 \mathrm{~cm}^{2}$ paper. The papers were rinsed with cold ethanol $66 \%\left(4{ }^{\circ} \mathrm{C}\right)$ for $30 \mathrm{~min}$, then twice with ethanol $66 \%$ at room temperature for $30 \mathrm{~min}$. After removing the ethanol, the papers were dipped in acetone for $2-3 \mathrm{~min}$ and dried. The papers were then transferred into scintillation vials. The radioactivity was measured using a liquid scintillation counter (LKB Wallac 1219; Perkin Elmer, Woodbridge, ON, Canada). 


\section{Glucose uptake bioassay}

$\mathrm{C} 2 \mathrm{C} 12$ myocytes were grown in 12 -well plates to $60 \%$ confluence then differentiated into myotubes over a 7day period. On day 6 of differentiation, $\mathrm{C} 2 \mathrm{C} 12$ cells were treated overnight (16-18 h) with either 0.1\% DMSO (vehicle control), the maximal non-toxic concentrations of CJ, FJ, each of the seven fractions $(12.5 \mu \mathrm{g} / \mathrm{mL})$ or each the four pure compounds (Additional file 1: Table S1). Metformin $(400 \mu \mathrm{M})$ was used as a positive control in similar conditions. After treatment, cells were rinsed twice with a warm Krebs phosphate buffer (KPB: $20 \mathrm{mM}$ Hepes, $4.05 \mathrm{mM} \quad \mathrm{Na}_{2} \mathrm{HPO}_{4}, \quad 0.95 \mathrm{mM}$ $\mathrm{NaH}_{2} \mathrm{PO}_{4}, 136 \mathrm{mM} \mathrm{NaCl}, 5 \mathrm{mM}$ glucose, $4.7 \mathrm{mM}$ $\mathrm{KCl}, 1 \mathrm{mM} \mathrm{CaCl} 2,1 \mathrm{mM} \mathrm{MgSO}$, $\mathrm{pH}$ 7.4) then incubated with $\mathrm{KPB}$ for $30 \mathrm{~min}$ at $37{ }^{\circ} \mathrm{C}$. At this point, insulin $(100 \mathrm{nM})$ was added to specific wells to act as another positive control (incubation in KPB buffer for $30 \mathrm{~min})$. Cells were then rinsed twice with warm glucose-free $\mathrm{KPB}$, then incubated in glucose-free $\mathrm{KPB}$ containing $0.5 \mu \mathrm{Ci} / \mathrm{mL}$ 2-deoxy- $\mathrm{D}-{ }^{3} \mathrm{H}$-glucose (TRK383, Amersham Biosciences, Baie d'Urfé, Canada) for $10 \mathrm{~min}$ at $37^{\circ} \mathrm{C}$. After incubation, cells were kept on ice and rinsed 3 times with ice-cold glucose-free $\mathrm{KPB}$ then lysed in $0.5 \mu \mathrm{L}$ of $\mathrm{NaOH}(0.1 \mathrm{M})$ for $30 \mathrm{~min}$. The lysates were transferred with $1 \mathrm{~mL}$ of water to scintillation vials, then $4 \mathrm{~mL}$ of liquid scintillation cocktail (Beckman Coulter, Fullerton, USA) was added to each vial and incorporated radioactivity was measured using a liquid scintillation counter (LKB Wallac 1219; Perkin Elmer, Woodbridge, ON, Canada).

\section{Statistical analysis}

All data were reported as the mean \pm SEM of 3 different experiments with triplicates for each sample. Results were analyzed by one-way analysis of variance (ANOVA) (post-hoc pairwise comparisons were carried out with Bonferroni correction). In case the requirement of homogeneity of variances was not fulfilled, GamesHowell test for post-hoc was used. All statistical analyses were carried out using SPSS software, version 24 (IBM Corporation, NY, USA). A $p$ value below 0.05 was considered statistically significant.

\section{Results}

\section{Cytotoxicity assay (LDH)}

After overnight treatment of H4IIE, HepG2 and differentiated $\mathrm{C} 2 \mathrm{C} 12$ cells with CJ, FJ, each of the seven fractions or each of the four pure compounds at different concentrations, LDH released and total LDH were measured for each condition. Additional file 1: Table S1 shows the maximum non-toxic concentration determined for each sample and each cell line based on the results of $\mathrm{LDH}$ test.
Fermented blueberry juice and its fractions decrease G6Pase activity and increase GS activation

As illustrated in Fig. 2a, FJ significantly decreased G6Pase activity (31\% reduction; $p<0.05)$ as compared to vehicle control ( $0.1 \%$ DMSO). This effect represented roughly half of the effect of the insulin positive control (67\% decrease). In contrast, CJ did not induce a significant change in the activity of G6Pase. After fractionation of FJ, the seven fractions were tested in the G6Pase bioassay and all of them showed varied, yet statistically significant, inhibitory effect on the enzyme's activity that ranged from 20 to $61 \%$ when compared to the DMSO ( $0 \%$ inhibition reference; Fig. 2a).

Figure $2 \mathrm{~b}$ presents results concerning GS activity. FJ induced a significant increase in the enzyme's activity (2.3 fold increase, $p<0.001$ ) identical to that of the

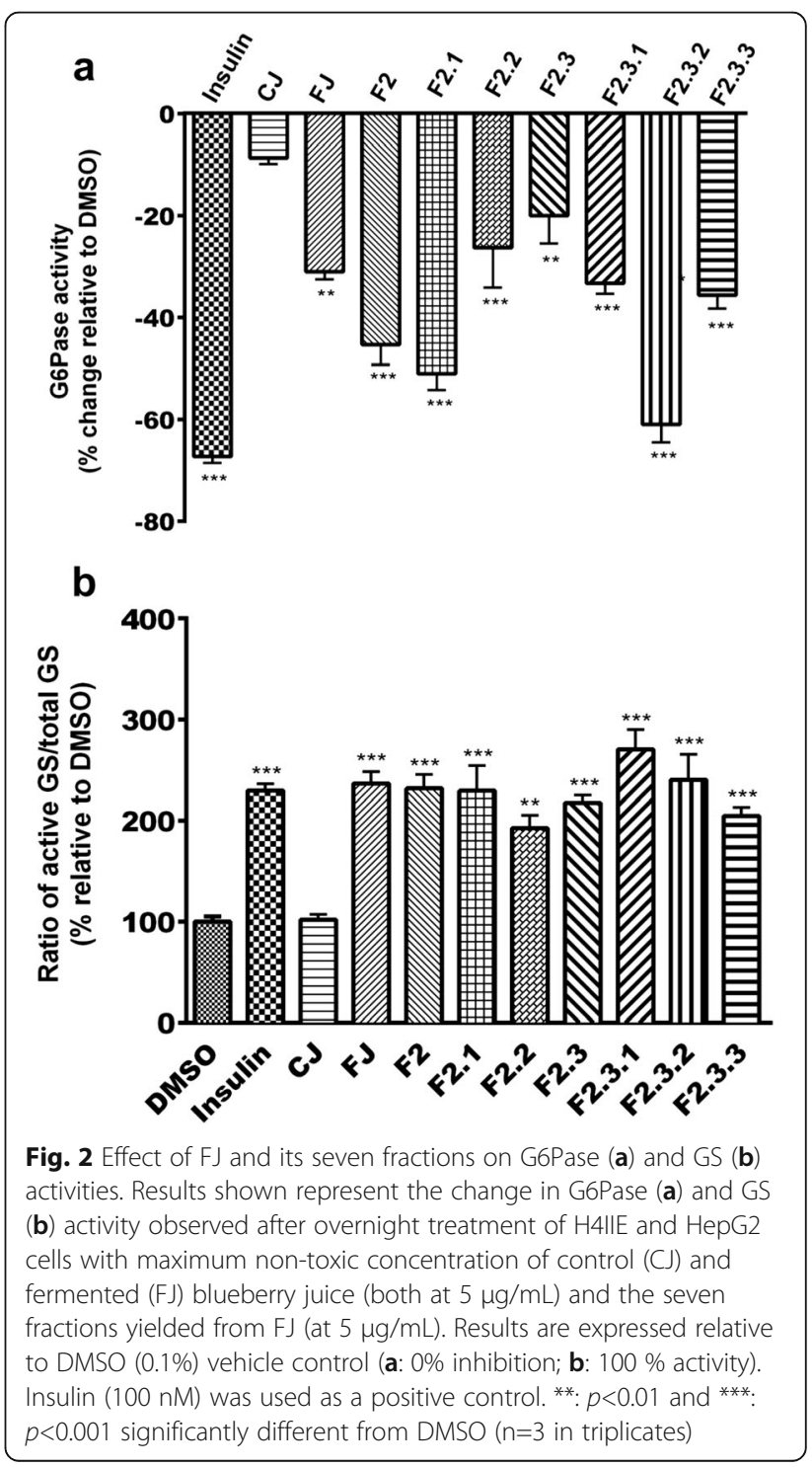


positive control, insulin (2.3 fold activation). As observed with G6Pase activity, CJ was without any significant effect. In addition, all seven fractions derived from FJ were able to significantly increase the activity of GS and ranged from 1.9- to 2.7-fold when compared to the DMSO vehicle control (100\% activation; Fig. 2b).

\section{Phenolic fractions enhance glucose uptake in $\mathrm{C} 2 \mathrm{C} 12$ muscle cells}

When tested for their ability to enhance glucose uptake in C2C12 muscle cells, FJ showed a $20 \%$ stimulation of this uptake $(p<0.01)$ whereas $C J$ was without any effect (similar to vehicle control, DMSO 0.1\%; Fig. 3). Insulin used as the positive control stimulated glucose transport into cells by $33 \%(p<0.001)$. The phenolic fraction (F2) along with its subfractions F2.1 and F2.2, F2.3.2 were able to enhance glucose uptake into muscle cells by 25,18 and $15 \%$ respectively $(p<$ $0.01)$. Bonferroni post hoc test did not reveal significant differences between FJ, F2, F2.1, and F2.2. The other fractions were without effect when compared to vehicle control (100\% activation; Fig. 3).

\section{Identification and isolation of phenolic compounds from the active fractions}

Results of G6Pase and GS activity as well as glucose uptake bioassays were used to guide the identification of compounds found in the active fractions. HPLC analysis confirmed that the three fractions F2, F2.1 and F2.2 were composed mainly of four phenolic compounds: chlorogenic acid (CA), gallic acid (GA), protocatechuic acid (PA) and catechol (Cat). Compound identification was confirmed by comparing retention times and UV-vis

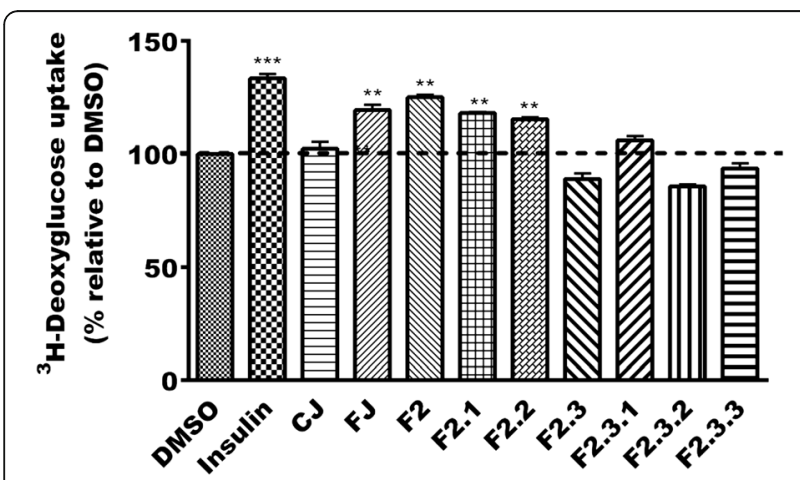

Fig. 3 Effect of FJ and its seven fractions on $3 \mathrm{H}$-deoxyglucose uptake. Results shown represent $3 \mathrm{H}$-deoxyglucoseuptake by $\mathrm{C} 2 \mathrm{C} 12$ cells after overnight treatment with maximum non-toxic concentration of control (CJ) and fermented (FJ) blueberry juice (both at 12.5 $\mu \mathrm{g} / \mathrm{mL}$ ) and the seven fractions yielded from FJ (at $12.5 \mu \mathrm{g} / \mathrm{mL}$ ). Results are expressed as percentage relative to DMSO (0.1\%) vehicle control. Insulin (100 nM) was used as a positive control. ${ }^{* *}: p<0.01$ and ***: $p<0.001$ significantly different from DMSO $(n=3$ in triplicates) profiles of each peak with respective standards (Fig. 4 and Additional file 1: Table S2). Calculation of phenolic compounds concentrations was based on the external standard method. The concentrations of individual phenolic compounds in FJ were as follows: CA $(3.0 \mathrm{mg} /$ g DW), GA (3.2 mg/g DW), PA (0.3 mg/g DW) and GA $(3.2 \mathrm{mg} / \mathrm{g} \mathrm{DW})$.

\section{Identification of GA and Cat as the most active compounds acting on key enzymes implicated in hepatic glucose output}

As mentioned above, the most active fractions (F2, F2.1 and F2.2) were rich in phenolic compounds mainly CA, GA, PA and Cat. These compounds were tested at their maximal non-toxic concentration in the G6Pase and the GS assays. Two of the four compounds, namely CA and PA, did not significantly decrease G6Pase activity as compared to DMSO. In contrast, GA was able to reduce the enzyme activity by $25 \%(p<0.05)$ whereas Cat yielded a $54 \%$ decrease in G6Pase activity (similar to the positive control, insulin) compared to the vehicle control DMSO $0.1 \%(p<0.001$, Fig. 5a). Games-Howell test showed that difference between Cat and GA was statistically significant $(p<0.05)$. In the GS assay, all of the four compounds were able to significantly increase the activity of the enzyme by about 2 fold (CA) or slightly less (GA, PA and Cat) when compared to DMSO $0.1 \%$ vehicle control $(p<0.05$, Fig. 5b). These effects compared favorably with the effect of insulin (2.3 fold increase). No statistically significant differences were detected between the compounds.

\section{Enhancement of glucose uptake by CA, GA and Cat}

Along with their ability to regulate key enzymes implicated in hepatic glucose output, CA, GA and Cat significantly enhanced glucose uptake in C2C12 cells by $15 \%$ $(p<0,01), 16 \%(p<0.05)$ and $43 \%(p<0.001)$ respectively. In contrast, PA had no effect when compared to the vehicle control DMSO 0.1\% (Fig. 6). Games-Howell test revealed that Cat yielded the greatest activity, it differed significantly from CA $(p<0.01)$ and GA $(p<0.05)$. $\mathrm{CA}$ and GA were not statistically different.

\section{Discussion}

Insulin resistance is an important risk factor for the development of T2D. Along with the decrease in the phosphorylation of insulin receptor substrates (IRS-1 and IRS-2) and in PI3-K activity observed in insulin resistance, the translocation of glucose transporters and the activity of key enzymes implicated in glucose homeostasis are also reduced [24]. Despite the presence of many hypoglycemic drugs in the market, the control of glycaemia is sometimes hard to achieve. Moreover, populations in Canada and the USA use natural health 


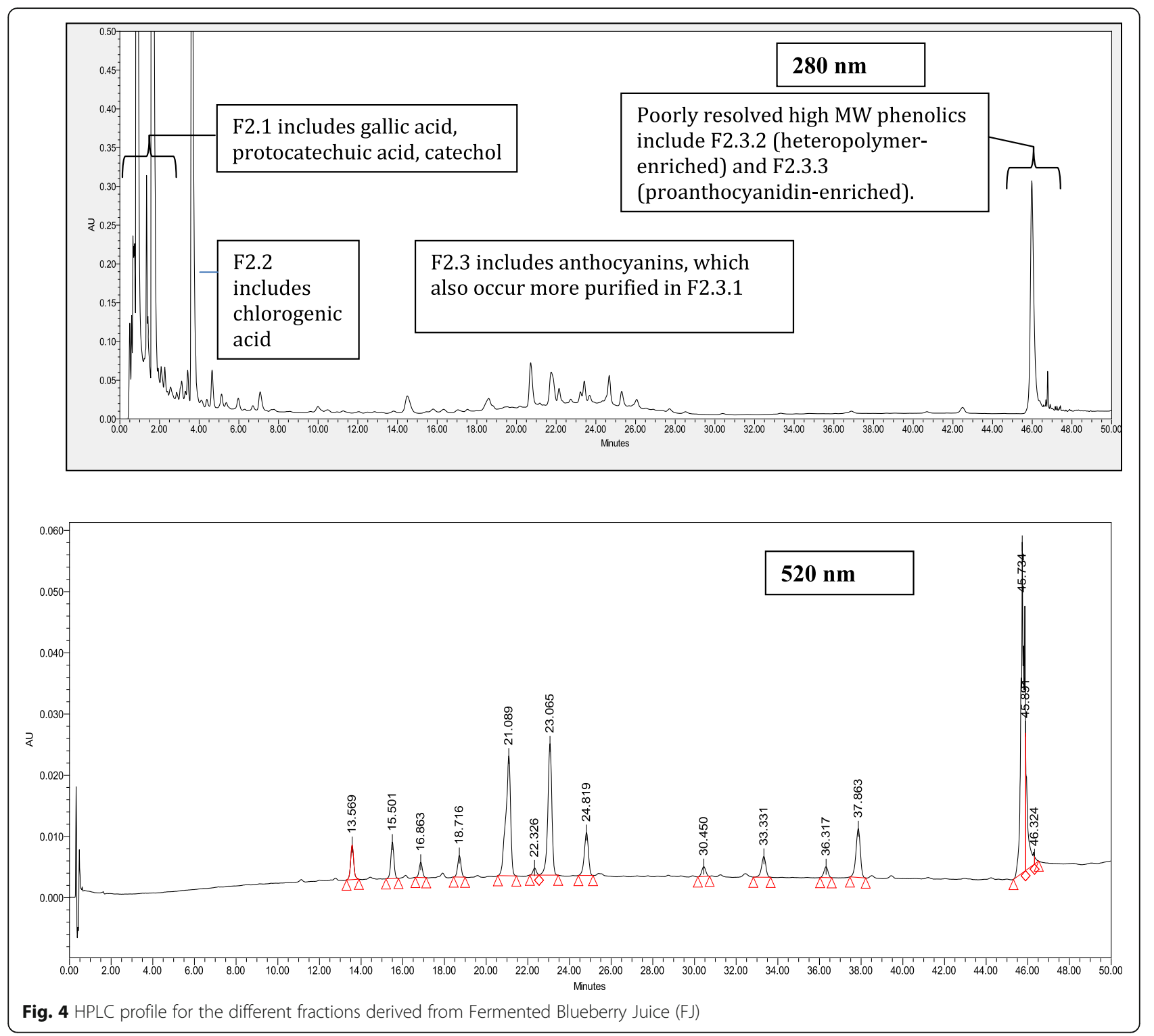

products alone or in combination with their oral hypoglycemic in order to better manage diabetes [3, 4].

Several parts of the Canadian "lowbush blueberry" (Vaccinium Angustifolium Ait) plant were previously shown by our group to exert antidiabetic activities [10]. A recent study by Klimis-Zakas et al. has reported the ability of a wild blueberry-enriched diet to reduce metabolic syndrome risk factors such as chronic inflammation and endothelial dysfunction in obese Zucker rats, a rat model for metabolic dysfunction [25]. Meanwhile, Matar and colleagues demonstrated that biotransformation of blueberry juice by the Serratia vaccinii bacteria conferred a new phytochemical profile to the juice [12]. HPLC evaluation of the phenolic profiles of the normal and fermented juices detected differences in the contents of flavonoids and organic acids. Notably, gallic acid, which was not detected in normal juice, reached concentrations that varied from $26.7 \pm 0.9$ to $64.6 \pm$ $0.5 \mathrm{mg} / \mathrm{kg} \mathrm{FW}$ in FJ. On the other hand, chlorogenic acid was rather abundant in FJ, being present at a concentration of $852.7 \pm 2.8 \mathrm{mg} / \mathrm{kg}$ FW. In general, total phenolic content nearly tripled after 3 days of fermentation (from $1251.3 \pm 278.7$ to $3640.3 \pm 201.1 \mathrm{mg}$ of gallic acid equivalent (GAE)/kg) and continued to increase modestly thereafter to reach $3926.3 \pm 194.3 \mathrm{mg}$ of GAE/ $\mathrm{kg}$ after 7 days of fermentation [12]. Moreover, fermented blueberry juice (FJ) not only exhibited an increase in phenolic content but was also characterized by more pronounced antioxidant activities compared to the normal juice (CJ) [12, 13, 21]. Our laboratories therefore combined efforts to examine the impact of fermentation on the antidiabetic potential of wild blueberry 


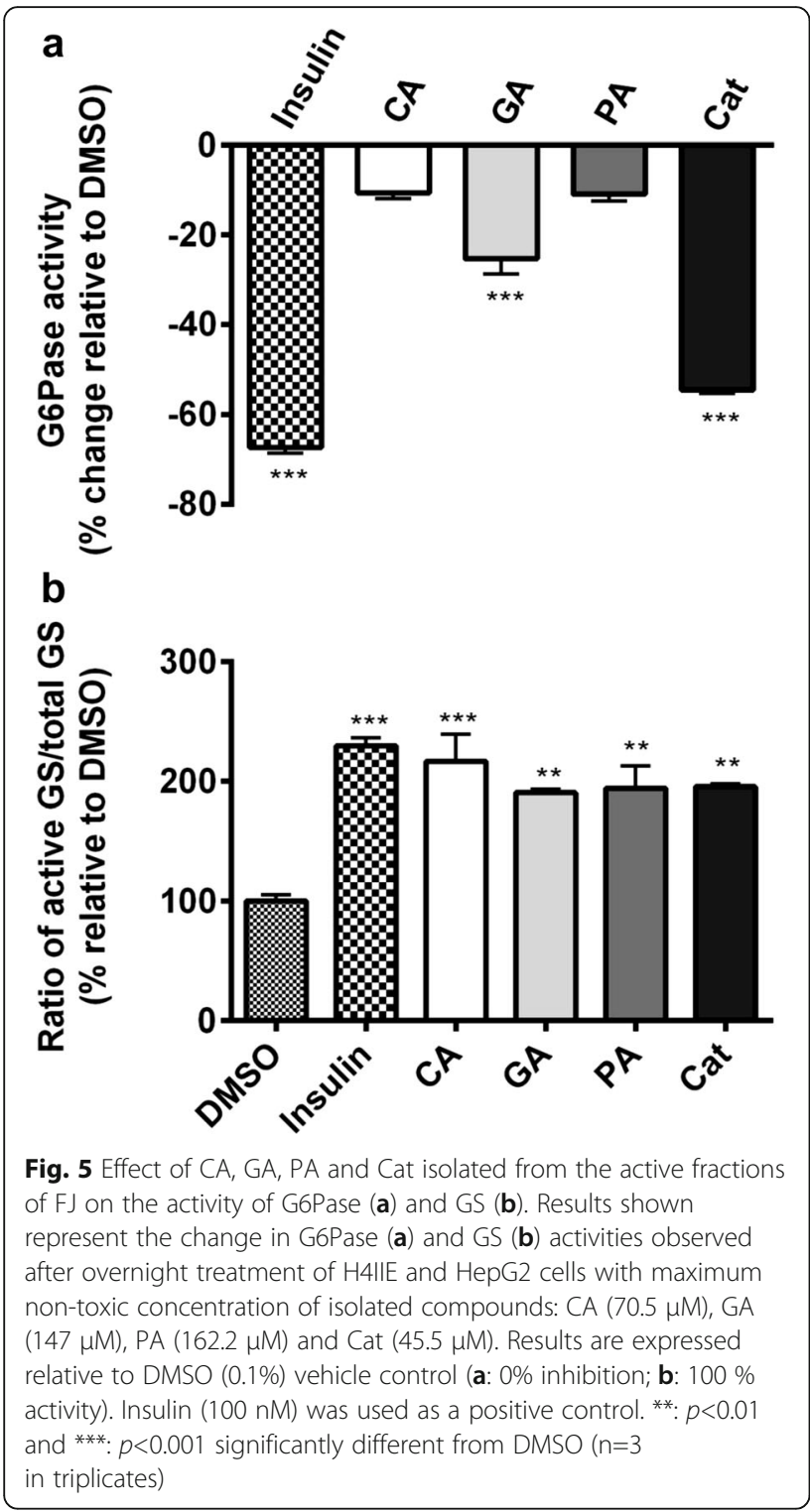

preparations. We found that fermentation conferred to blueberry juice the capacity to enhance glucose uptake in muscle cells and adipocytes via phosphorylation of AMPK [13].

In the current studies, we first chose to further evaluate the antidiabetic potential of $\mathrm{FJ}$ by assessing ratelimiting enzymes of gluconeogenesis (G6Pase) and glycogen synthesis implicated in hepatic glucose output. Indeed, the regulation of hepatic glucose production, along with glucose utilization by peripheral tissues like muscle and fat, are key regulators of systemic glycaemia $[17,26]$. We first compared effects of crude preparations of control and fermented blueberry juice. Consistent with our previous studies showing that fermentation conferred antidiabetic potential, we found that fermented blueberry juice significantly affected hepatocellular

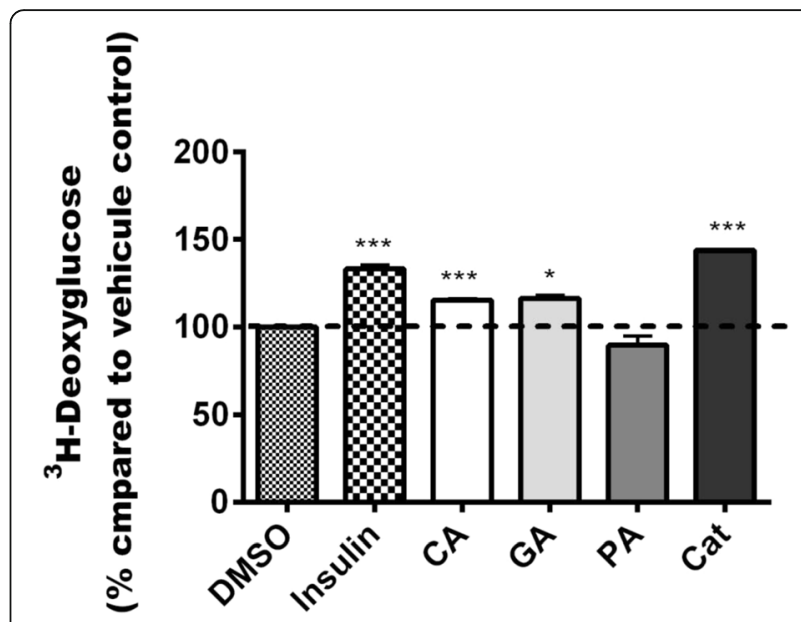

Fig. 6 Effect of CA, GA, PA and Cat isolated from the active fractions of $\mathrm{FJ}$ on $3 \mathrm{H}$-deoxyglucose uptake. Results shown represent $3 \mathrm{H}$ deoxyglucose uptake by C2C12 cells after overnight treatment with maximum non-toxic concentration of isolated compounds: CA (70.5 $\mu \mathrm{M}), \mathrm{GA}(147 \mu \mathrm{M}), \mathrm{PA}(162.2 \mu \mathrm{M})$ and Cat (45.5 $\mu \mathrm{M})$. Results are expressed as percentage relative to DMSO (0.1\%) vehicle control. Insulin (100 nM) was used as a positive control. *: $p<0.05$ and ***: $p<0.001$ significantly different from DMSO ( $n=3$ in triplicates)

glucose homeostasis while control blueberry juice was without effect. Indeed, FJ significantly inhibited G6Pase (to a level roughly half as potent as insulin) and enhanced GS activity (to a level similar to insulin) in cultured murine and human hepatocytes, respectively. These results thus indicate that fermentation of blueberry juice also confers it the potential to control hepatic glucose output by reducing glucose production and increasing glucose storage. We also confirmed our previous finding in $\mathrm{C} 2 \mathrm{C} 12$ cells [13] by demonstrating that our fermented blueberry preparation increased glucose transport whereas normal juice extract did not. This ascertained that the current lyophilized preparations behaved similarly to the actual juice that was used in these previous experiments.

Secondly and importantly, the current studies sought to isolate active fractions/compounds participating in the antidiabetic activity of the FJ in the muscle and liver cell bioassays of glucose homeostasis by using a phytochemical fractionation approach that we carried out previously to examine the protective effects of $\mathrm{CJ}$ on cardiomyocytes [27]. This approach yielded seven polyphenolic fractions of FJ, which were tested in the G6Pase, GS and glucose uptake bioassays. FJ fractions were able to significantly decrease G6Pase activity to levels ranging from 20 to $61 \%$. The heteropolymerenriched fraction, F2.3.2, gave the highest effect, which was very close to that of the positive control insulin. Unfortunately, the complexity of this fraction precluded further sub-fractionation. Next in apparent potency were the F2 and F2.1 fractions, the latter being enriched in 
GA, PA and Cat. In contrast, all FJ phenolic fractions increased the activity of GS within a relatively narrow range (1.9- to 2.7- fold increase), which was comparable to the action of the insulin positive control.

In terms of glucose uptake in skeletal muscle cells, on the other hand, significant glucose transport activity was associated only with three phenolic-enriched fractions, namely F2, F2.1 and F2.2. Since all fractions were active to varying degrees in both G6Pase and GS assays but only these three phenolic fractions showed a significant effect on glucose uptake, we examined in greater detail the constituents of the latter fractions. HPLC analysis revealed that the phenolic fractions contained mainly four compounds, namely chlorogenic acid (CA), gallic acid (GA), protochatecuic acid (PA) and catechol (Cat). These compounds are known for their antioxidant activity. Many studies also showed additional beneficial effects of CA, GA and PA. Indeed, CA has demonstrated anti-inflammatory, anti-diabetic, neuro-protective and cardio-protective properties [28-31]. GA exerts antidiabetic activities [32], improves hyperglycaemia and glucose tolerance [33], while offering protection against diabetes complications, notably through cardioprotective properties [34, 35]. On the other hand, PA possesses anti-inflammatory $[36,37]$ and anti-apoptotic properties [38]. It also improves angiogenesis [39] and protects against hepatotoxicity and nephrotoxicity [40]. In contrast, and to our knowledge, no recent studies have addressed effects of catechol on glucose metabolism. Thus, our study is the first to reveal the effect of these phenolic compounds on hepatic glucose homeostasis and glucose transport in muscle.

The four compounds were able to increase GS activity to levels similar to those observed for FJ and its active fractions. GA and Cat showed stronger effects than the two others on the reduction of G6Pase activity. This effect was close to that observed for FJ and its active fractions. In terms of glucose transport, PA was inactive; GA and CA had similar effects, whereas Cat had the most pronounced activity. Interestingly, Cat stands out in this study as having the best activity profile in almost all bioassays, yielding equivalent if not stronger effects than FJ and its phenolic active fractions themselves.

\section{Conclusion}

Altogether, the results of this study confirmed that fermentation of blueberry juice confers it antidiabetic potential in liver and skeletal muscle cells through the regulation of key hepatic enzymes implicated in gluconeogenesis and glycogen synthesis and the enhancement of skeletal muscle glucose uptake. Using a phytochemical fractionation approach, we now demonstrate that this activity resides principally in phenolic fractions and can be attributed, at least in part, to CA, GA, PA and Cat.
This is congruent with studies showing antidiabetic properties for CA and GA, whereas it uncovers novel beneficial actions for PA. As mentioned, however, of all pure compounds in our study, Cat stood out as the most promising constituent, showing activity similar to or higher than the parent FJ (and even the insulin control) in all three bioassays. Future studies will be needed to further examine effects of flavonoids, anthocyanins, heteropolymers and proanthocyanins present in FJ.

Our study thus provides important insights into novel potential antidiabetic molecules that are produced when blueberry juice is fermented with Serratia vaccinii. Importantly, the identified compounds represent quality control tools that can be used to ensure the efficacy of FJ and hence standardize FJ preparations.

\section{Additional file}

Additional file 1: Table S1. A. Optimum non-toxic concentrations of CJ, FJ and corresponding fractions used for bioassays in H4IIE, HepG2 and C2C12 cells. B. Maximum non-toxic concentrations of pure compounds used for bioassays in H4IIE, HepG2 and C2C12 cells. Table S2. Fractionation of fermented blueberry extract, indicating the major component(s) in each fraction (F). (DOCX $19 \mathrm{~kb}$ )

\section{Abbreviations \\ AMPK: AMP- activated protein kinase; Antho: Anthocyanins fraction; CA: Chlorogenic acid; Cat: Catechol; CJ: Control blueberry juice; \\ FJ: Fermented blueberry juice; Flv: Flavonoids fraction; G6Pase: Glucose-6- Phosphatase; GA: Gallic acid; GLUT4: Glucose transporter 4; GS: Glycogen Synthase; GSK-3: Glycogen Synthase kinase-3; Hetero: Heteropolymers fraction; IRS: Insulin Receptor Substrate; PA: Protocatechuic acid; PAC: Proanthocyanidins fraction; PGC-1a: Peroxisome proliferator-activated receptor gamma coactivator 1 -alpha; Phe: Phenolic fraction}

\section{Acknowledgments}

The project was carried out in collaboration with BioAtlantech and Vaccinium Technologies, Fredericton, New Brunswick, Canada; special thanks are expressed to John Argall and Denise Philpott. We also wish to thank Dr John Thor Arnason of the University of Ottawa for valuable discussions and advice.

\section{Funding}

This study was funded by Agriculture and AgriFood Canada through its "Developing Innovative Agrifood Products" (DIAP) program (no 5025).

Availability of data and materials

The datasets supporting the conclusions of this article are included within the manuscript and its supplementary information files.

\section{Authors' contributions}

AN performed the biological activities, data analysis and wrote the manuscript. HME performed the statistical analysis, interpreted data, wrote and critically revised the manuscript. MVT performed the fractionation and HPLC analysis. WK and CM collaborated by providing precious professional advice for the phytochemical analysis, fermentation and fractionation of the juice. TV prepared the fermented juice. PSH is the supervisor and the corresponding author. All co-authors read, commented and approved the final manuscript.

\section{Competing interests}

The authors declare that they have no competing interests.

Consent for publication

Not applicable. 


\section{Ethics approval and consent to participate}

Not applicable.

\begin{abstract}
Author details
'Natural Health Products and Metabolic Diseases Laboratory, Department of Pharmacology and Physiology, Université de Montréal, Station Centre-Ville, P.O. Box 6128, Montréal, Québec H3C 3J7, Canada. ${ }^{2}$ Canadian Institutes of Health Research Team in Aboriginal Antidiabetic Medicines and Montreal Diabetes Research Center, Montreal, Canada. ${ }^{3}$ Department of Pharmacognosy, University of Beni-Suef, Beni-Suef, Egypt. ${ }^{4}$ Food chemistry, Agriculture and Agri-Food Canada, Government of Canada, Kentville, Nova Scotia, Canada. ${ }^{5}$ Department of Nutritional Sciences, Faculty of Health Sciences, University of Ottawa, Ottawa, Canada.
\end{abstract}

\section{Received: 10 September 2016 Accepted: 23 February 2017} Published online: 04 March 2017

\section{References}

1. Riaz M, Zia-Ul-Haq M, Saad B. The role of anthocyanins in obesity and diabetes. In: Anthocyanins and human health: biomolecular and therapeutic aspects. Cham: Springer International Publishing; 2016.

2. Fandriks $L$. Roles of the gut in the metabolic syndrome: an overview. J Intern Med. 2016. doi:10.1111/joim.12584. [Epub ahead of print]

3. Nahas R, Moher M. Complementary and alternative medicine for the treatment of type 2 diabetes. Can Fam Physician. 2009;55(6):591-6.

4. Esmail N. Complementary and AlternativeMedicine in Canada: Trends in Use and Public Attitudes, 1997-2006. In: Public Policy Sources, vol. 87. Vancouver: The Fraser Institute; 2007.

5. Koupy D, Kotolova H, Kucerova J. Effectiveness of phytotherapy in supportive treatment of type 2 diabetes mellitus Billberry (Vaccinium myrtillus). Ceska Slov Farm. 2015;64(1-2):3-6.

6. Haddad PS, Depot M, Settaf A, Cherrah Y. Use of antidiabetic plants in Morocco and Quebec. Diabetes Care. 2001;24(3):608-9.

7. Stull AJ, Cash KC, Johnson WD, Champagne CM, Cefalu WT. Bioactives in blueberries improve insulin sensitivity in obese, insulin-resistant men and women. J Nutr. 2010;140(10):1764-8.

8. Edirisinghe I, Burton-Freeman B. Anti-diabetic actions of Berry polyphenols Review on proposed mechanisms of action. J Berry Res. 2016;6:237-50.

9. Seymour EM, Tanone II, Urcuyo-Llanes DE, Lewis SK, Kirakosyan A, Kondoleon MG, Kaufman PB, Bolling SF. Blueberry intake alters skeletal muscle and adipose tissue peroxisome proliferator-activated receptor activity and reduces insulin resistance in obese rats. J Med Food. 2011; 14(12):1511-8

10. Martineau LC, Couture A, Spoor D, Benhaddou-Andaloussi A, Harris C, Meddah B, Leduc C, Burt A, Vuong T, Le Mai P, et al. Anti-diabetic properties of the Canadian lowbush blueberry Vaccinium angustifolium Ait. Phytomedicine. 2006;13(9-10):612-23.

11. Song $Y$, Huang $L, Y u J$ J. Effects of blueberry anthocyanins on retinal oxidative stress and inflammation in diabetes through $\mathrm{Nrf} 2 / \mathrm{HO}-1$ signaling. J Neuroimmunol. 2016:301:1-6.

12. Martin LJ, Matar C. Increase of antioxidant capacity of the lowbush blueberry (Vaccinium angustifolium) during fermentation by a nove bacterium from the fruit microflora. J Sci Food Agric. 2005;85(9):1477-84

13. Vuong T, Martineau LC, Ramassamy C, Matar C, Haddad PS. Fermented Canadian lowbush blueberry juice stimulates glucose uptake and AMPactivated protein kinase in insulin-sensitive cultured muscle cells and adipocytes. Can J Physiol Pharmacol. 2007;85(9):956-65.

14. Vuong T, Benhaddou-Andaloussi A, Brault A, Harbilas D, Martineau LC, Vallerand D, Ramassamy C, Matar C, Haddad PS. Antiobesity and antidiabetic effects of biotransformed blueberry juice in KKA(y) mice. Int J Obes (Lond). 2009;33(10):1166-73.

15. Han HS, Kang G, Kim JS, Choi BH, Koo SH. Regulation of glucose metabolism from a liver-centric perspective. Exp Mol Med. 2016:48:e218

16. Oh KJ, Han HS, Kim MJ, Koo SH. CREB and FoxO1: two transcription factors for the regulation of hepatic gluconeogenesis. BMB Rep. 2013;46(12):567-74

17. Anyamaneeratch $K$, Rojvirat $P$, Sukjoi $W$, Jitrapakdee S. Insights into transcriptional regulation of hepatic glucose production. Int Rev Cell Mol Biol. 2015:318:203-53.

18. Dieni CA, Bouffard MC, Storey KB. Glycogen synthase kinase-3: cryoprotection and glycogen metabolism in the freeze-tolerant wood frog. J Exp Biol. 2012;215(3):543-51.
19. Leto $D$, Saltiel AR. Regulation of glucose transport by insulin: traffic control of GLUT4. Nat Rev Mol Cell Biol. 2012;13(6):383-96.

20. Matchett MD, MacKinnon SL, Sweeney MI, Gottschall-Pass KT, Hurta RA. Inhibition of matrix metalloproteinase activity in DU145 human prostate cancer cells by flavonoids from lowbush blueberry (Vaccinium angustifolium): possible roles for protein kinase $C$ and mitogen-activated protein-kinase-mediated events. J Nutr Biochem. 2006;17(2):117-25.

21. Vuong T, Matar C, Ramassamy C, Haddad PS. Biotransformed blueberry juice protects neurons from hydrogen peroxide-induced oxidative stress and mitogenactivated protein kinase pathway alterations. Br J Nutr. 2010;104(5):656-63.

22. Nachar A, Vallerand D, Musallam L, Lavoie L, Badawi A, Arnason J, Haddad PS. The action of antidiabetic plants of the canadian james bay cree traditional pharmacopeia on key enzymes of hepatic glucose homeostasis. Evid Based Complement Alternat Med. 2013;2013:189819.

23. Thomas JA, Schlender KK, Larner J. A rapid filter paper assay for UDPglucose-glycogen glucosyltransferase, including an improved biosynthesis of UDP-14C-glucose. Anal Biochem. 1968;25(1):486-99.

24. Abdul-Ghani MA, DeFronzo RA. Pathogenesis of Insulin Resistance in Skeletal Muscle. J Biomed Biotechnol. 2010;2010:19. Article ID 476279. doi: 10.1155/2010/476279.

25. Klimis-Zacas D, Vendrame S, Kristo AS. Wild blueberries attenuate risk factors of the metabolic syndrome. J Berry Res. 2016:6(2):225-36.

26. Mues C, Zhou J, Manolopoulos KN, Korsten P, Schmoll D, Klotz LO, Bornstein $\mathrm{SR}$, Klein HH, Barthel A. Regulation of glucose-6-phosphatase gene expression by insulin and metformin. Horm Metab Res. 2009;41(10):730-5.

27. Louis XL, Thandapilly SJ, Kalt W, Vinqvist-Tymchuk M, Aloud BM, Raj P, Yu L, Le H, Netticadan T. Blueberry polyphenols prevent cardiomyocyte death by preventing calpain activation and oxidative stress. Food Funct. 2014;5(8):1785-94.

28. Cheng DM, Pogrebnyak N, Kuhn P, Krueger CG, Johnson WD, Raskin I. Development and phytochemical characterization of high polyphenol red lettuce with anti-diabetic properties. PLoS One. 2014;9(3):e91571.

29. Shen W, Qi R, Zhang J, Wang Z, Wang H, Hu C, Zhao Y, Bie M, Wang $Y, F u Y$, et al. Chlorogenic acid inhibits LPS-induced microglial activation and improves survival of dopaminergic neurons. Brain Res Bull. 2012;88(5):487-94.

30. Hwang SJ, Kim YW, Park Y, Lee HJ, Kim KW. Anti-inflammatory effects of chlorogenic acid in lipopolysaccharide-stimulated RAW 264.7 cells. Inflamm Res. 2014;63(1):81-90.

31. Li Y, Shen D, Tang X, Li X, Wo D, Yan H, Song R, Feng J, Li P, Zhang J, et al. Chlorogenic acid prevents isoproterenol-induced hypertrophy in neonatal rat myocytes. Toxicol Lett. 2014;226(3):257-63.

32. Kade IJ, Ogunbolude Y, Kamdem JP, Rocha JB. Influence of gallic acid on oxidative stress-linked streptozotocin-induced pancreatic dysfunction in diabetic rats. J Basic Clin Physiol Pharmacol. 2014;25(1):35-45.

33. Bak EJ, Kim J, Jang S, Woo GH, Yoon HG, Yoo YJ, Cha JH. Gallic acid improves glucose tolerance and triglyceride concentration in diet-induced obesity mice. Scand J Clin Lab Invest. 2013;73(8):607-14.

34. Umadevi S, Gopi V, Vellaichamy E. Inhibitory effect of gallic acid on advanced glycation end products induced up-regulation of inflammatory cytokines and matrix proteins in H9C2 (2-1) cells. Cardiovasc Toxicol. 2013;13(4):396-405.

35. Ramkumar KM, Vijayakumar RS, Vanitha P, Suganya N, Manjula C, Rajaguru P, Sivasubramanian S, Gunasekaran P. Protective effect of gallic acid on alloxan-induced oxidative stress and osmotic fragility in rats. Hum Exp Toxicol. 2014;33(6):638-49.

36. Del Corno M, Varano B, Scazzocchio B, Filesi C, Masella R, Gessani S. Protocatechuic acid inhibits human dendritic cell functional activation: role of PPARgamma up-modulation. Immunobiology. 2014;219(6):416-24.

37. Wei M, Chu X, Guan M, Yang X, Xie X, Liu F, Chen C, Deng X. Protocatechuic acid suppresses ovalbumin-induced airway inflammation in a mouse allergic asthma model. Int Immunopharmacol. 2013;15(4):780-8.

38. Deng JS, Lee SD, Kuo WW, Fan MJ, Lin YM, Hu WS, Huang YC, Velmurugan BK, Tsai FJ, Tsai CH, et al. Anti-apoptotic and pro-survival effect of protocatechuic acid on hypertensive hearts. Chem Biol Interact. 2014;209:77-84.

39. Kang Z, Zhu H, Jiang W, Zhang S. Protocatechuic acid induces angiogenesis through PI3K-Akt-eNOS-VEGF signalling pathway. Basic Clin Pharmacol Toxicol. 2013:113(4):221-7.

40. Adefegha SA, Omojokun OS, Oboh G. Modulatory effect of protocatechuic acid on cadmium induced nephrotoxicity and hepatoxicity in rats in vivo. Springerplus. 2015;4:619. 